\title{
Coordination chemistry of rare earths: syntheses, structure, spectroscopy and chemical bonding
}

\author{
Guang-Xian Xu,Jinqing Ren,Chun-Hui Huang and Jin-Guang Wu \\ Department of Chemistry, Feking University,Beijing,China
}

\begin{abstract}
The molecular and electronic structure of mononuclear,dinuclear,polynuclear complexes and clusters of rare earths are discussed systematically, by an extended INDO method made applicable to treat $4 f$-compounds, with respect to the nature of chemical bonding and factors influencing the coordination number and structural types of lanthanide complexes and organometallics.Some recent investigations in our laboratory on the synthesis,molecular and electronic structure of some novel peroxy-bridging tetranuclear lanthanide complexes will also be discussed.
\end{abstract}

\section{INTRODUCTION}

In recent years the coordination and organometaliic chemistry of rare earths have become one of the most fruitful and exciting fields of study. The successful syntheses of numerous novel rare earth compounds and their peculiar optical, magnetic, superconducting and catalytical properties not only attract extraordinary interests from experimental chemists but also give a great challenge in theoretical aspects.

The partially filled $4 f$-subshell of lanthanide compounds exhibits special optical and magnetic behaviour. The theoretical analjsis of these phenomena is usually undertaken in terms of ligand field theory.However, for the study of chemical behaviour, such as the catalytic activities and the long-standing controvercy over the nature of chemical bonding of $4 \mathrm{f}$-organometallics, and also for the prediction of new lanthanide compounds, it is more appropriate to use the molecular orbital theory.

In order to apply the molecular orbital theory for the calculation of the electronic structure of lanthanide compounds, we have extended the INDO formalism to $4 f$ orbitals, derived all the expressions needed for the SCF Mo calculations involving $4 f$ atomic orbitals and evaluated VOIP, Slater and Racah parameters from the most recent spectral data (ref.1-3). An INDO program suitable for the lanthanide compounds was written and published (ref.2). It is well-known that the choice of the basic set of atomic orbitals is very important in ab initio as well as approximate Mo calculations. Therefore we have proposed a set of double zeta wave functions of the $4 f$ orbitals for the whole series of lanthanides.The optimized Slater exponents and the corresponding extension coeficients were obtained to fit the best Hartree-Fock numerical $4 f$ orbitals of lanthanide elements (ref.4).

\section{MONONUCLEAR COMPLEXES AND ORGANOMETALLICS}

There are several long-atanding controversies and questions in 4f-coordination and organometallic chemistry. They are: (1) What is the nature of lanthenide-ligand bonding, covalent or ionic? (2) If covalent, which orbitals contribute to bonding, $5 d, 6 \mathrm{~s}, 6 \mathrm{p}$ or $4 \mathrm{f}$ ? (3) Why the coordination number of In atom or ion can vary in such a wide range from 3 to 12 ? What factors determine the C.N.?(4) Under what conditions it will be possible to form polynuclear In complexes and clusters?

1. Mononuclear complexes with C.N. $=3$ are very scarce. Bradley et al. in 1973 (ref.5) synthesized.

$$
\operatorname{Ln}\left(N\left(\mathrm{SiMe}_{3}\right)_{2}\right)_{3}, \mathrm{Ln}=\mathrm{Sc}, \mathrm{Y}, \mathrm{Ce}, \mathrm{Pr}, \mathrm{Nd}, \mathrm{Sm}, \mathrm{Eu}, \mathrm{Gd}, \mathrm{Ho}, \mathrm{Yb}, \mathrm{Lu}
$$




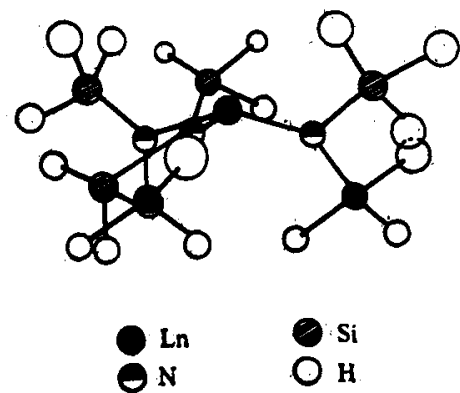

Fig.l Structure of $\mathrm{InL}_{3}$ $I=N\left(\mathrm{SiM \theta}_{3}\right)_{2}$

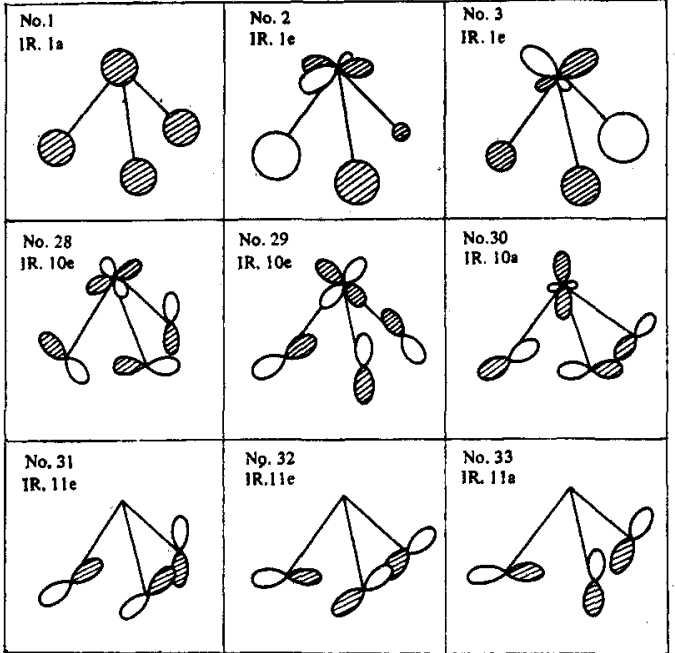

Fig.2 Schematic Diagram of Some MO's of NaL3

Table I Theoretical Explanation of the Pyramidal Structure of $\mathrm{NdL}_{3}$

\begin{tabular}{|c|c|c|c|c|c|c|}
\hline \multirow{2}{*}{$\begin{array}{l}\text { Bond Angle } \\
\text { of } \mathrm{N}-\mathrm{Nd}-\mathrm{N} / \\
\text { Degree }\end{array}$} & \multirow{2}{*}{$\begin{array}{l}\text { Overlap In- } \\
\text { tegral of } \\
\mathrm{Nd}-\mathrm{N}\end{array}$} & \multicolumn{4}{|c|}{ Mulliken Bond Order } & \multirow{2}{*}{$\begin{array}{l}\text { Net Charge } \\
\text { on } N\end{array}$} \\
\hline & & $\mathrm{Nd}(\sigma s)-\mathrm{N}$ & $N d(6 p)-N$ & $\mathrm{Nd}(5 d)-\mathrm{N}$ & $\mathrm{Nd}-\mathrm{N}$ & \\
\hline 120 & -0.172 & 0.079 & 0.116 & 0.435 & 0.630 & 0.637 \\
\hline 115 & 0.386 & 0.084 & 0.111 & 0.452 & 0.641 & 0.503 \\
\hline 100 & 0.438 & 0.094 & 0.103 & 0.457 & 0.654 & 0.421 \\
\hline 90 & 0.293 & 0.095 & 0.100 & 0.456 & 0.651 & 0.415 \\
\hline 80 & 0.055 & 0.093 & 0.097 & 0.452 & 0.642 & 0.433 \\
\hline
\end{tabular}

Fig. 1 shows the molecular structure of $\mathrm{LnL}_{3}$. We have studied the electronic structure and chemical bonding of this compound by INDO method (ref.6). The results may be summarized as follows: (a) The net charge on $N d$ atom is only 0.254 , so that the $N d-N$ bonds are mainly covalent in character. (b) The covalency of the bond is due to the participation of $5 \mathrm{~d}, 6 \mathrm{~s}$ and $6 \mathrm{p}$ orbitals of the central Nd atom, while the three $4 f$ electrons are more than $99 \%$ localized at the Nd atom. (c) Table 1 shows that the Mulliken bond order of the Nd-N bond is maximum at bond angle of $N-N d-N$ equal to $100^{\circ}$, which explains the pyramidal structure of the molecule. (d) Since the central lanthanide atom has nine valence orbitals: $(5 d),(6 s)$ and $(6 p)$, it tends to assume high coordination number by polymerization or reaction with other neutral ligands such as solvent molecules unless there are bulky substituent groups $R$ in the amide ligand $\mathrm{NR}_{2}$. Therefore the presence of the bulky trimethyl silicon group $\mathrm{R}$ is a very important criterion for the existence of the discrete lanthanide complex $\mathrm{LnL}_{3}$ with coordination number as small as three due to the steric hindrance agalnst self polymerization.

2. Mononuclear complexes with C.N. $=4$ are also scarce. Hart et al. in 1968 first reported a purely sigma bonded derivative,Li(LnPh ) (ref.7); but after structure determination, it was found that the anion $\operatorname{LnPA}_{4}$ is not a discrete complex with $\mathrm{C.N} .=4$, but polymerize to higher C.N.In 1972, F.A.Cotton, F.A.Hart et al. (ref.8) reported the synthesis and structural determination of tetrakis(2,6-dimethylphenjl) lutetiate anion.This was the first complex of lanthanides with C.N. =4, arranged in tetrahedral configuration. We have studied the electronic structure and chemical bonding in this anion complex by INDo method ( $r e f .8$ ).Fig.3 shows the schematic diagram of some MO's of

$$
\text { Lu(2,6-dimethylphenyl) } 4
$$

Fig. 4 gives the charge distribution of the simplified complex anion LuPh $^{-}$. It may be seen that the net charge on Lu atom is 0.948 , so that the Lu-C 4 bond is mainly covalent with about $31 \%$ ionic character. The Mulliken bond order of Lu-C is 0.497 . 


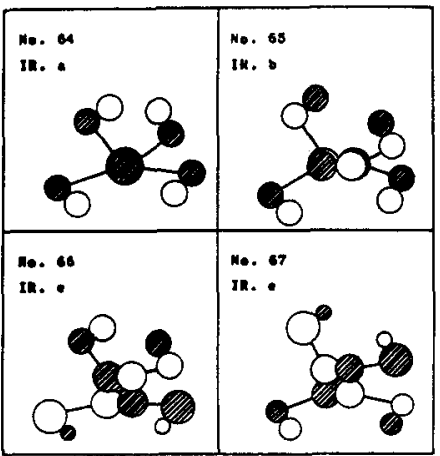

Fig. 3 Schematic Diagram of Some MO's of $\operatorname{Lu}(2,6 \text {-dimethylphengl })_{4}^{-}$

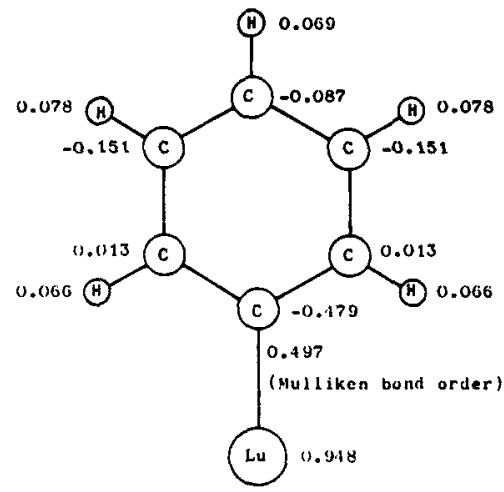

Fig. 4 Net Charge Distribution of $\mathrm{LuPh}_{4}$

3. Mononuclear complexes with C.N. =5 are also scarce. The following complex may be an example,but its structure has not been reported yet.

$$
\mathrm{LnCl}_{3} \text { (phenanthroline) }
$$

4. Mononuclear complexes with C.N. $=6$ are not common also. The anion

$$
\operatorname{Er}(\mathrm{NCS}) 6^{3-} \operatorname{in}\left(\left(\mathrm{C}_{4} \mathrm{H}_{9}\right)_{4} \mathrm{~N}\right)_{3} \operatorname{Er}(\mathrm{NCS})_{6} \quad \text { (Martin et al.,1968) }
$$

is an example.Here the presence of the bulky tetrabutylammonium cation is an important criterion for the existence of this lanthanide complex.

5. Mononuclear complexes with C.N. $=7$ In our laboratory, as a part of a project to study the rare earth complexes with neutral organophosphorus extractants, Huang et al. (ref.9) have synthesized a neodymium complex with C.N. =7, $\mathrm{Nd}(\mathrm{NCS})_{3}\left(\mathrm{Ph}_{3} \mathrm{PO}\right)_{4^{\circ}}$ The crystal and molecular structure have been determined by a Nicolet Model R3 Four-circle X-ray Diffractometer. The crystal is monoclinic with space group $\mathrm{P} 21 / \mathrm{c}$. The unit cell parameters are

$$
\begin{aligned}
& a=13.211(7) \& \quad \text { beta }=102.19(5)^{\circ} \quad Z=4 \\
& \begin{array}{lll}
\mathrm{b}=23.544(14) \text { o } & \mathrm{F}(000)=2924 \mathrm{e} & \mathrm{d}_{\mathrm{calc}}=1.370 \mathrm{~g} / \mathrm{cm}^{3} \\
\mathrm{c}=22.821(18) & \mathrm{V}=6943 \mathrm{~A}^{3} & \mathrm{~d}^{2} \mathrm{expt}=1.375 \mathrm{~g} / \mathrm{cm}^{3}
\end{array} \\
& c=22.821 \text { (18) } \quad V=6943 \AA \quad d_{\text {expt }}=1.375 \mathrm{~g} / \mathrm{cm}^{3}
\end{aligned}
$$

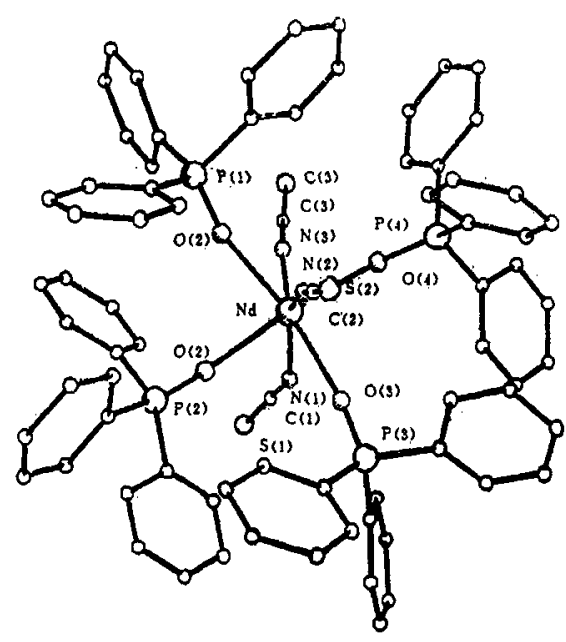

Fig. 5 Structure of $\mathrm{Na}(\mathrm{NCS})_{3}\left(\mathrm{Ph}_{3} \mathrm{PO}\right)_{4}$

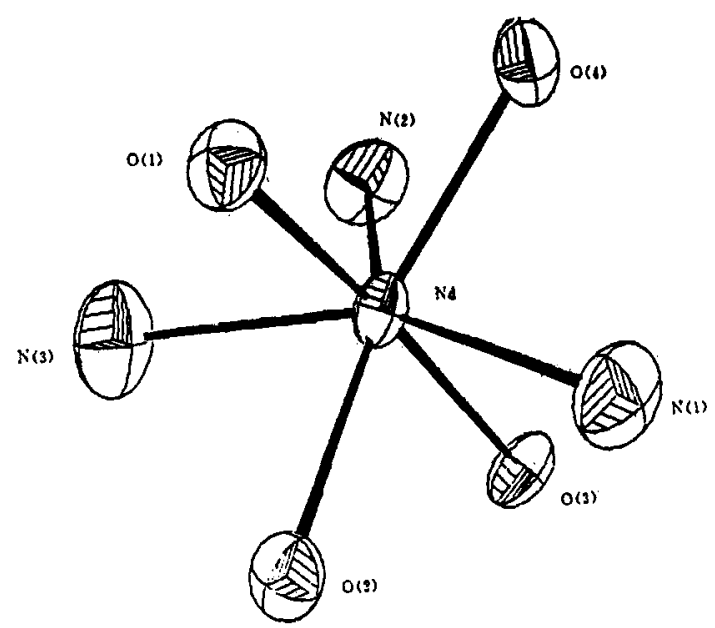

Fig.6 The Coordination Sphere of Neodymium 
'lhe molecule has an approximate Cs symmetry as shown in Fig.5. It has three covalent $N d-N$ bonds with an average bond length of $2.50 \AA$ and four dative covalent bonds with neutral triphenyl phosphine oxide ligands, the average length of the dative $\mathrm{Nd}-\mathrm{O}$ bond is $2.39 \mathrm{A.Fig.6}$ shows the coordination sphere of Neodymium.

6. Mononuclear complexes with C.N. =8 Li,Ni,Xu and Ren ( $r e f .10$ ) have studied the electronic structure and chemical bonding in the 15-crown-5 complex of lanthanum trichloride having $\mathrm{C} \cdot \mathrm{N} \cdot=8$.

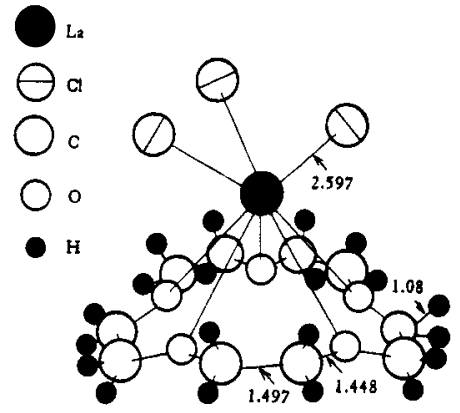

Fig.7 Molecular Structure of

$$
\mathrm{LaCl}_{3}(15-\mathrm{crown}-5)
$$

(Numbers in the figure are bond lengths in $\AA$ )

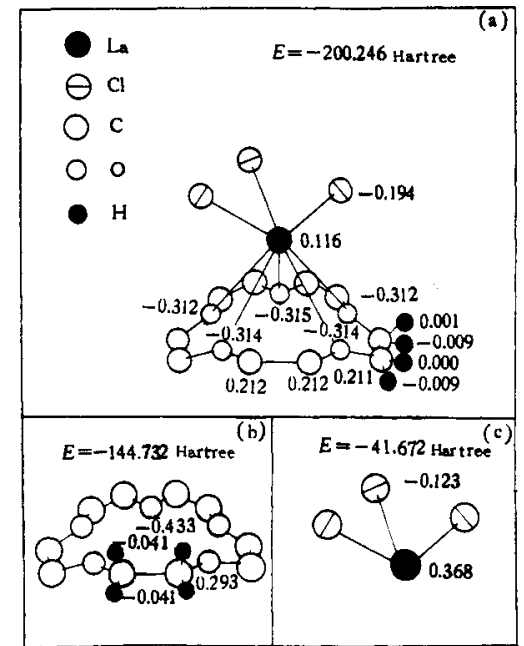

Fig. 8 Charge distribution of

(a) $\mathrm{LaCl}_{3}(15-\mathrm{crown}-5)$

(b) 15-crown-5

(c) $\mathrm{LaCl}_{3}$

7. Mononuclear complexes with C.N. $=9$ Huang et al. (ref.ll) have prepared $\theta$ neodymium complex, $\mathrm{Nd}\left(\mathrm{NO}_{3}\right)_{3}\left(\mathrm{Ph}_{3} \mathrm{PO}\right)_{2}\left(\mathrm{C}_{2} \mathrm{H}_{5} \mathrm{OH}\right)$, and determined its crystal and molecular structure having C.N.=9. But we shall only discuss the electronic structure and chemical bonding in a pi-bonded complex,trisindenyl samarium, with $C \cdot N \cdot=9 \cdot(\operatorname{ref} .12)$.

Fig. 9 shows the molecular structure of $\mathrm{Sm}$ (ind) 3 ,Fig. 10 gives the schematic diagrams of some MO's of Sm(ind) 3 .<smiles>[SnH3]C1CCCCC1</smiles>

C

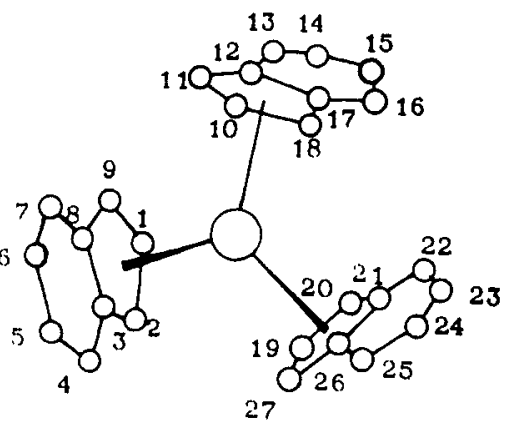

Fig. 9

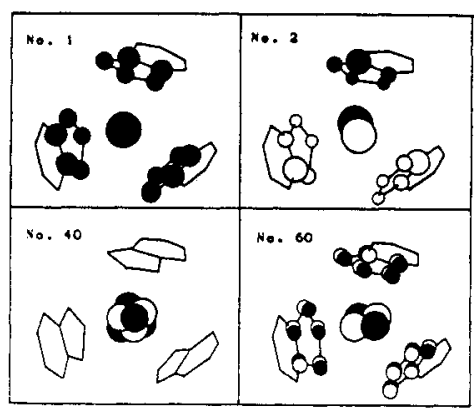

Fig. 10

Schematic diagrams of some MO's of $\mathrm{Sm}\left(\mathrm{C}_{9} \mathrm{H}_{7}\right)_{3}$ 
From Fig.10 it may be seen that the MO No.l of the lowest energy is due to the overlapping of the $6 \mathrm{~s}$ orbital of $\mathrm{Sm}$ and the $\mathrm{C} 2 \mathrm{p}$ pi-orbitals of the five membered rings of the three indenyl ligands, while the four other $c 2 p$ piorbitals of the six-membered ring do not participate to the bonding with Sm. MO No 2 is due to the overlapping of $6 \mathrm{p}$ orbitals of $\mathrm{Sm}$ with the five-membered rings of indenyl ligands.MO No.60 is of much higher energy and due to the overlapping of $5 \mathrm{~d}$ of $\mathrm{Sm}$, while the Mo No.40 is strongly localized to $4 f$ of $\mathrm{Sm}$, without any interaction with the ligands. The net charge on Sm atom is only 0.471 , so that the Sm-ligand pi-bond s are mainly covalent in character.0ther details of the electronic structure may be refered to ref.12.

8. Mononuclear complexes with C.N. $=10$ D.R.Rogers et al.(1980) synthesized $\mathrm{Cp}_{3} \mathrm{Gd}(\mathrm{THF})$ and determined its structure, which has $\mathrm{C}$.N.=10. We have studied its electronic structure and bonding (Ren and $X u$, to appear).

9. Mononuclear complexes with C.N. $=11$ are very rare.One example worthwhile to mention is $\mathrm{IaCp}_{3}\left(\mathrm{CH}_{3} \mathrm{CN}\right)_{2}$.

10. Mononuclear complexes with C.N. $=12$ In our laboratory, Huang et al. (ref.13) synthesized ( $\left.\left.\left(\mathrm{C}_{4} \mathrm{H}_{9}\right){ }^{\mathrm{N}}\right) 3^{\mathrm{Nd}\left(\mathrm{NO}_{3}\right)}\right)_{\text {and }}$ determined its molecular and crystal structure and found that the nitrate ligands are bidentate, so that the C.N. of $\mathrm{Nd}$ is 12. That means there are 24 valence electrons surrounding the central Nd atom, but INDO calculation (Ren,Huang and Xu, to appear) reveals that the $4 f$ orbitals of Nd remain strongly localized, only nine valence orbitals, $5 \mathrm{~d}, 6 \mathrm{~s}$ and $6 \mathrm{p}$ participape to bonding with the bidentate nitrate ligands, the six excess valence electrons being located at the nonbonding orbitals of the ligands.

\section{DINUCLEAR COMPLEXES AND ORGANOMETALLICS}

1. Dinuclear complexes with C.N. $=\mathbf{5}$ or less are rather rare.The following oxygen bridging, sigma-bonded complex is an example.Here, as in the mononuclear complexes, the presence of bulky ligands is very important for low $\mathrm{C} . \mathrm{N}$.

$$
\begin{aligned}
& \mathrm{La}\left(\mathrm{N}\left(\mathrm{SiMe}_{3}\right)_{2}\right)_{3}+\mathrm{Ph}_{3} \mathrm{PO}+\mathrm{O}_{2} \longrightarrow \\
&\left(\mathrm{Ph}_{3} \mathrm{PO}\right)\left(\mathrm{N}\left(\mathrm{SiMe}_{3}\right)_{2}\right)_{2} \mathrm{La}(\mathrm{mu}-0)_{2} \mathrm{Ia}_{\mathrm{a}}\left(\mathrm{N}\left(\mathrm{SiMe}_{3}\right)_{2}\right)_{2}\left(\mathrm{Ph}_{3} \mathrm{PO}\right) \\
&(\text { Bradley et al ., I } 974)
\end{aligned}
$$

2. Dinuclear complexes with C.N. $=8$ are rather common.M.L.Ely et al.synthesized $\mathrm{Cp}_{2} \mathrm{Yb}(\mathrm{mu}-\mathrm{Me})_{2} \mathrm{YbCp}_{2}$ and J.Holton et al.(ref.14) determined its structure as shown in Fig.1l. We studied its electronic structure (ref.15).Fig.12 shows the schematic diagram of the MO's corresponding to the bridging methyl bonds. Fig. 13 gives the charge distribution of the complex.

The carboxylate bridging lanthanide complexes usually crystallize in polymeric chains.Zhang et al.(ref.16) have succeeded to prepare a dimeric Nd complex by using a bulky neopentanoic acia to prevent from polymerization. The structure was determined and shown in Fig.14.

$O^{{ }^{c} b}$

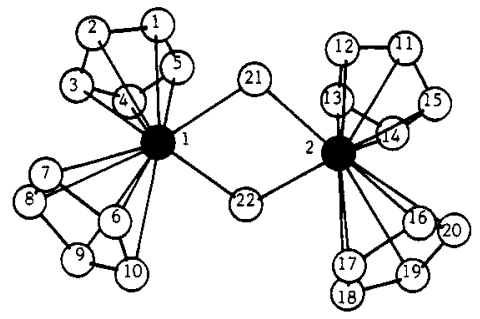

Fig.lI structure of $\left(\mathrm{YbCp}_{2} \mathrm{Me}\right)_{2}$
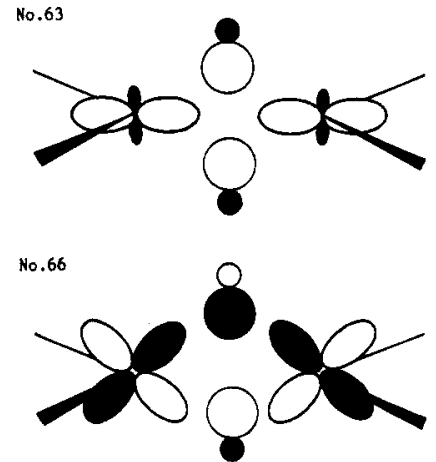

Fig.12 MO's of bridge bonds 

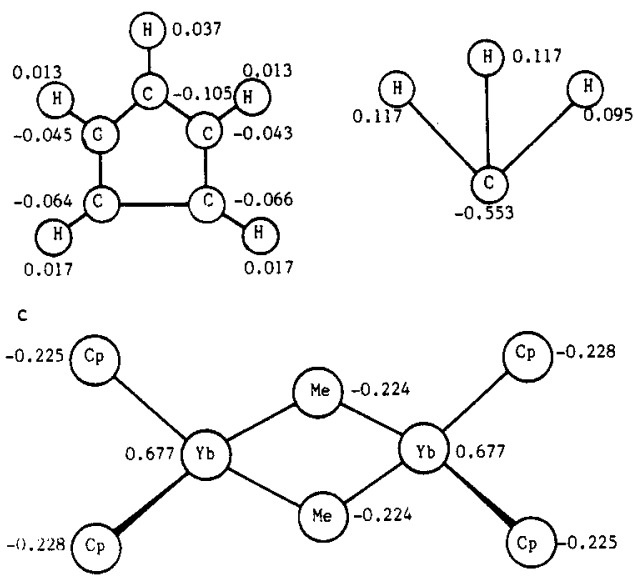

Fig.13 Charge Distribution of $(\mathrm{YbCp}, \mathrm{Me})_{2}$

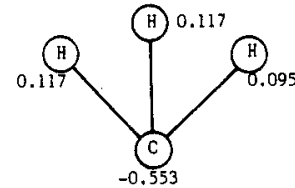

Fig.14 Structure of Dimeric Nd Complex with Neopentanoic Acid

3. Dinuclear complexes with C.N. $=9$ The following complex is an example.

$\left(\mathrm{MeC}_{5} \mathrm{H}_{4}\right)_{2}(\mathrm{THF}) \mathrm{Er}(\mathrm{mu}-\mathrm{H})_{2} \mathrm{Er}(\mathrm{THF})\left(\mathrm{MeC}_{5} \mathrm{H}_{4}\right)_{2}$

(E.C.Baker et al.,1975; W.J.Evans et al.,1982)

4. Dinuclear complexes with C.N. $=11$ is very rare.Huang et al. in our laboratory ( $r e f .17$ ) have prepared a compound, in which there is a novel eleven-coordinate nitrate bridging dinuclear neodymium complex, the structure of which has been determined as shown in Fig.15. Using a localized INDO program,we also studied the electronic structure and bonding of this interesting complex. Figs. 16 and 17 show the contour diagram of the bonding between the two Nd atoms and the bridging nitrate group.

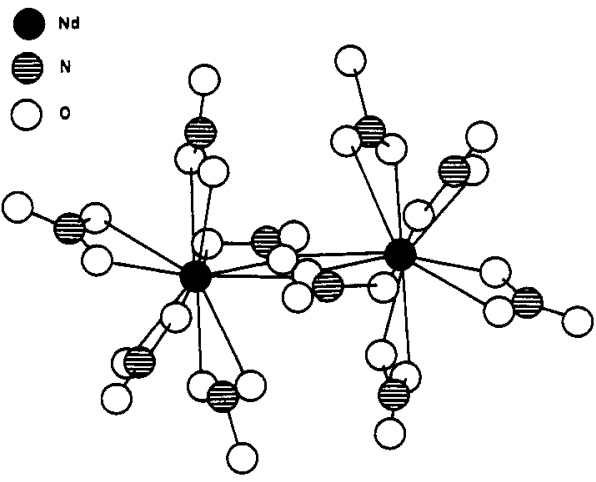

Fig. 15 Structure of $\mathrm{Nd}_{2}\left(\mathrm{NO}_{3}\right)_{40} 0^{4-}$
in $\left(\mathrm{Me}_{3} \mathrm{C}_{16} \mathrm{H}_{33} \mathrm{~N}^{-}\right)$
$\left.4 \mathrm{Nd}_{2}\left(\mathrm{NO}_{3}\right)_{10}\right)$
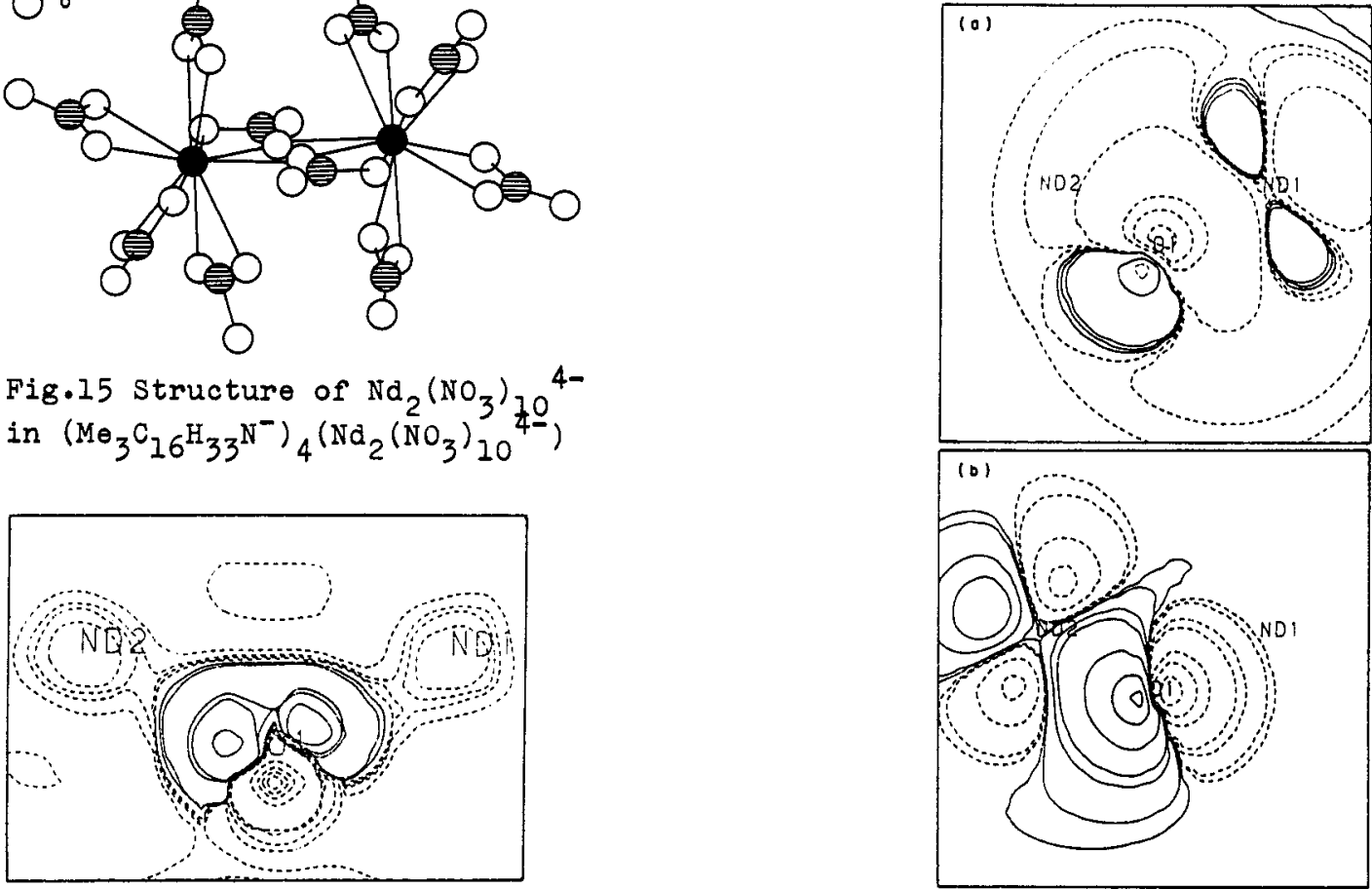

Fig. 16 Contour diagram of the nitrate bridge bond between two Nd atoms (a)

Fig. 17 Contour diagram of the nitrate bridge bond between two Nd atoms (b) (c) 


\section{POLYNUCLEAR COMPLEXES AND CLUSTERS}

1. Dioxygen bridging tetranuclear complexes In our laboratory, we have recently synthesized four novel series of complexes having the following formulations $(r \in f .18)$ :

$$
\begin{array}{ll}
\mathrm{In}_{4} \mathrm{O}_{4} \mathrm{Cl}_{8}(\mathrm{THF})_{8}\left(\mathrm{H}_{2} \mathrm{O}\right)_{2} \cdot 2 \mathrm{THF} & \mathrm{Ln}_{4} \mathrm{O}_{4} \mathrm{Cl}_{8}(\mathrm{THF})_{6}\left(\mathrm{H}_{2} \mathrm{O}\right)_{4} \cdot 2 \mathrm{THF} \\
\mathrm{Ln}_{4} \mathrm{O}_{4} \mathrm{Cl}_{8}(\mathrm{THF})_{2}\left(\mathrm{H}_{2} \mathrm{O}\right)_{8} \cdot 4 \mathrm{THF} & \mathrm{Ln}_{4} \mathrm{O}_{4} \mathrm{Cl}_{8}(\mathrm{THF})_{2}\left(\mathrm{H}_{2} \mathrm{O}\right)_{8} \cdot 2 \mathrm{H}_{2} \mathrm{O}
\end{array}
$$

where $\mathrm{In}=\mathrm{Pr}, \mathrm{Nd}, \mathrm{Sm}$ and THF is tetrahydrofurane. The crystal and molecular structure of them have been determined by $x$-ray diffraction method.

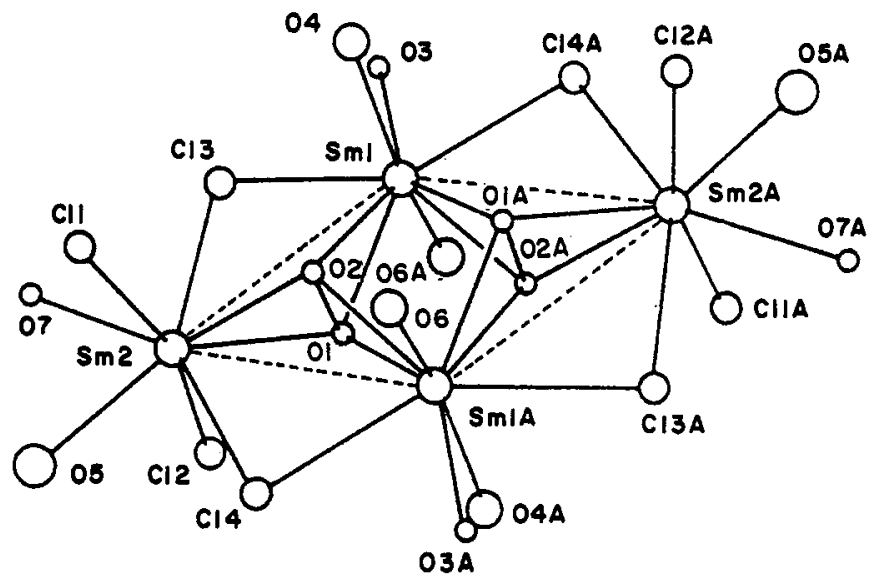

Fig.18 Structure of $\mathrm{Sm}_{4} \mathrm{O}_{4} \mathrm{Cl}_{8}(\mathrm{THF})_{6}\left(\mathrm{H}_{2} \mathrm{O}\right)_{4}$

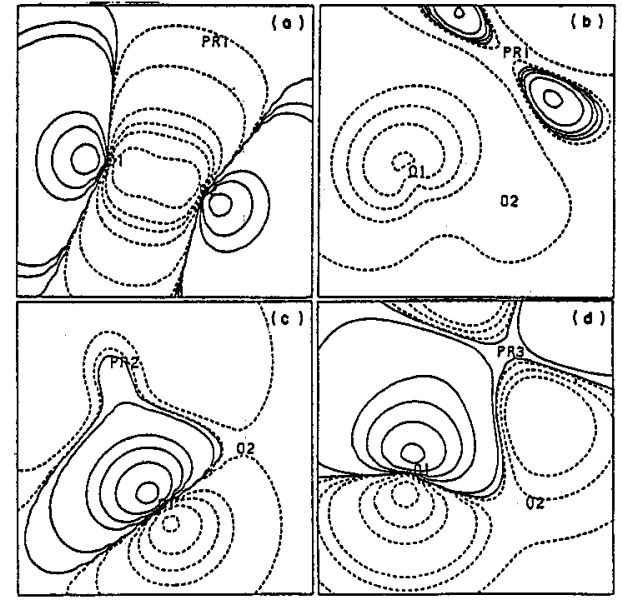

Fig.19 Contour maps of dioxygen bridge to three in atoms (ref.19)

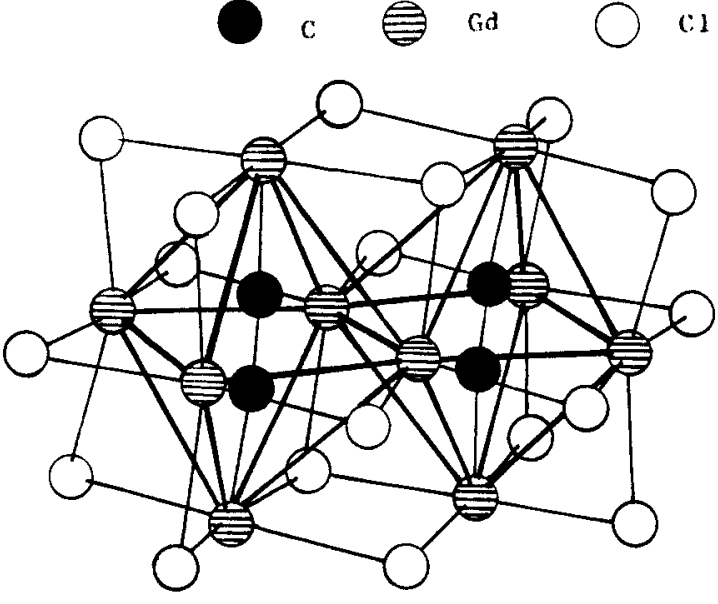

Fig.20 Structure of $\mathrm{Gd}_{10} \mathrm{C}_{4} \mathrm{Cl}_{18}$

2. Polynuclear lanthanide clusters The electronic structure and chemical bonding in the cluster, $\mathrm{Gd}_{10} \mathrm{C}_{4} \mathrm{Cl}_{18}$, whose structure was determined by E. Warkentin et al. ( $r e f .20$ ) as $\mathrm{ghown}^{-1}$ Fig.20, was studied by us (ref.2I). The results show that the bonding is covalent in character rather than ionic. Mulliken population analysis gives that the net charges on all atoms in the cluster are nearly neutral. The contribution to covalent bonding is mainly due to the $5 d, 6 \mathrm{~s}$ and $6 \mathrm{p}$ orbitals of $\mathrm{Gd}$, while the $4 \mathrm{f}$ orbitals are strongly localized. The $\mathrm{C}_{2}$ unit in the center of each Gd octahedron, in which there is a C-C single bohd, is combined with six neighboring Gd atoms by two Gd-C single bonds and eight Gd -C "half bonds", so that the total valence of C remains equal to 4 . The Mulliken bond order between Gd * Gd is only 0,265 . 


\section{REFERENCES}

1. Lemin Li,Jinging Ren and Guang-Xian Xu (K.H.Hsu), International J.Quantum Chemistry, 23,1305-1316(1983).

2. Jinqing Ren, Lemin $L i$ and Guang-Xian Xu (K.H.Hsu), Acta Sci.Univ.Peking No.3,30-48,49-62(1982); No.4,37-49(1983).

3. Jinqing Ren, Lemin $\mathrm{Li}$ and Guang-Xian $\mathrm{Xu}$ (K.H.Hsu), Chemical J.of Chinese Universities, 4(6),745-750(1983).

4. Jinqing Ren and Guang-Xian Xu, J.Molecular Science, $2(2), 13(1984)$.

5. D.C.Bradley,J.S.Ghotra and F.A.Hart,J.C.S.,Dalton Trans., 1021(1973).

6. Jinqing Ren and Guang-Xian Xu, Scientia Sinica, Series $B, 30,337-346$ (1987).

7. F.A.Hart and M.S.Saran, Chem.Commun.,1614(1968).

F.A.Cotton, F.A.Hart,M.B.Hurthouse and A.J.Welsh, Chem.Commun., 1225(1972).

8. Jinqing Ren and Guang-Xian Xu, "New Frontiers in Rare Earth Science and Applications",pp.273-277, Editor,Guang-Xian Xu and Jimei Xiao, Science Press, Beijing, China (1985).

9. Chunhui Huang, Rongfang Xu,Xiaoji Xu and Guang-Xian Xu,J.Inorganic Chem. (China), 1,103-112(1985).

10. Zhen-xiang Li,Jia-zuan Ni,Guang-Xian $\mathrm{Xu}$ and Jinqing Ren, Kexue Tongbeo, 31 (14), 956-962(1986).

11. Chunhui Huang, Genbei Ii, Yongfen Zhou, Tianzhu Jin and Guang-Xian Xu, Acta Sci.Univ.Peking, No.6,12-20(1985).

12.Jinqing Ren and Guang-Xian Xu,J.of Chinese Universities,I(5),441-447 (1986).

13. Chunhui Huang,Piaokuo Li, et al., Acta Sci.Univ.Peking, No.5,42-50(1984).

14.J.Hol ton,M.F.Lappert, et al., Chem.Commun., 480(1976).

15.Guang-Xian Xu(K.H.Hsu) and Jinqing Ren, International J.of Quantum Chemistr ,29,1017-1024(1986).

16.De-long Zhang, Chunhui Huang,Guang-Xian $X u$ and Zuo-hua $P$ an, XXV ICCC

17. Chunhui Huang, Xianglin Jin,Yuping Xia and Guang-Xian Xu, Scientia Sinica Series B,903(1986).

18. Yinzhang Lin, Jinguang Wu, Jiuxin Gian, Yanping Chen and Guang-Xian Xu, XXV ICCC.

19.Guangdi Yang, Yinzhang Iin, Jinguang Wu and Guang-Xian Xu, J.Inorg.Chem. (China) (submetted).

20.E.Warkentin,R.Masse and A.Simon, Z.anorg.allgem. Chemie, 491, 323(1982).

21.Jinqing Ren and Guang-Xian Xu, Lanthanide and Actinide Research (in press). 